\section{FROM THE JOURNALS}

Lake SR, Vernon SA. Emergency contraception and retinal vein thrombosis. Br J Opthalmol 1999; 83: 630-631.*

This appears to be the first case in the literature of venous thromboembolism attributed to hormonal emergency contraception. Retinal vein thrombosis was diagnosed in a 33-year-old woman after she took PC4. She had onset of unilateral blurred vision the day after the treatment. Neither her personal nor family history is given relating to predisposing factors. Blood biochemistry and clotting factor screen were normal. The condition had resolved within 2 months.

Although both RCGP and Oxford-FPA cohort studies have suggested a possible small excess risk of retinal vascular disease in recent COC users, this disease grouping included other diagnoses such as retinal artery occlusion, retinal haemorrhage and vitreous haemorrhage. Existing faculty guidance gives a past history of thromboembolism as a relative contraindication to use of the Yuzpe regimen; this single case report should not result in more restrictive advice to use of oestrogen-containing emergency contraception. Obviously none of this is relevant to progestogen-only emergency contraception, which is preferable in patients with a history of thromboembolism anyway.

\section{*Sam Rowlands, MD, MRCGP, MFFP Medical Director, EPIC, Regeneration House, York Way, London, UK}

Sellors J, Walter S, Howard M. A new visual indicator of chlamydial cervicitis? Sex Transm Inf 2000; 76: 46-48.**

This was an interesting paper from Canada which aimed to determine if endocervical discharge opacity was a risk factor for chlamydial infection. The study comprised 1418 women from two family planning clinics, a termination of pregnancy clinic and a student health clinic. For all women the opacity and colour of endocervical discharge and whether there was easily induced mucosal bleeding was noted and an endocervical Chlamydia swab was taken. It showed a statistically significant correlation between each of the three clinical indicators and Chlamydia infection. The strongest correlation was the presence of a combination of opaque and yellow discharge $(\mathrm{OR}=4.9)$. The combination of all three indicators was the most specific. Would this improve the effectiveness of selective screening? Kamwendo F, Forslin L, et al.
Epidemiology of ectopic pregnancy during a 28-year period and the role of pelvic inflammatory disease. Sex Transm Inf 2000; 76: 28-32.**

This large Swedish study supports the idea that a reduction of PID will be associated with a decline of ectopic pregnancies, after a lag time. It showed a sharp increase in the incidence of ectopic pregnancies from 1970 until the 1990s, when it dropped by approximately $30 \%$. However, the PID admissions during this time peaked early on (1975-1979) and thereafter decreased to an all time low in the last 3 years of study.

**M Poulton, MRCP, Dip GUM Registrar, The Lawson Unit, Department of GUM, Royal Sussex County Hospital, Sussex, UK

Dominik R, Trussell J, Walsh T. Failure rates among perfect users and during perfect use: a distinction that matters. Contraception 2000; 60: 315-320.***

This publication is related to an article previously published in The British Journal of Family Planning: Trussell J. Contraceptive efficacy of the personal hormone monitoring system Persona. $\mathrm{Br}$ J Fam Plann 1999; 25: 34-35.

Hubacher D, Goco N, Gonzalez B, Taylor D. Factors affecting DMPA continuation rates. Contraception 2000; 60: 345-351.***

Various articles have concentrated on the discontinuation of depot medroxyprogesterone acetate (DMPA) in relation to side effects. This article looks at the impact of the service provider on discontinuation rates when DMPA was introduced to Bolivia. The methodology looked at the advice recorded by the provider in clinics and at interviews with the women participating in the project. The interviews were undertaken by nonclinical staff in the women's homes and the data collection concentrated on the quality of services that the women had experienced. Three hundred and fiftytwo women were successfully interviewed from 430 initially participating in the study.

Those women who were told to return to the clinic if worried about side effects were more likely to continue with the method. Also, those women that had received information on efficacy, side effects and amenorrhoea were more likely to continue.

Even though the overall discontinuation rate of the method was within that recorded by other studies, this article does show that good counselling and imparting of information makes a woman less likely to discontinue the DMPA.

***Judy Murty, MB, ChB, DRCOG, MFFP SCMO Leeds Community Family Planning Services; Consultant for Marie Stopes International; 19 Swingsty Court, Clifton, York

Christin-Maitre S, Bouchard $\mathrm{P}$, and Spitz IM. Medical Termination of Pregnancy. New Engl J Med 2000; 342: $946-956$. $* * * *$

The authors, from Paris and New York, describe the situation in the USA regarding legal termination of pregnancy. Eighty-six percent of counties have no abortion facilities. In spite of this, the USA has one of the highest abortion rates among developed countries. They refer to current difficulties: 'indeed, access to abortion is becoming increasingly difficult in the United States because of harassment of both patients and health care personnel'.

There follows a review of medical termination of pregnancy in the first trimester, with a detailed description of the relevant physiology and the pharmacology of all medical methods. Efficacy and side effects are described with an extensive review of the literature, with 100 references. This paper should be particularly useful to those involved with abortion who wish to understand the pros and cons of the options available.

Backman T, Huhtala S, et al. Length of use and symptoms associated with premature removal of the levonorgestrel intrauterine system: a nation-wide study of 17360 users. $\mathrm{Br}$ J Obstet Gynaecol 2000; 107: 335339.****

A Questionnaire was sent to all users of the levonorgestrel intra-uterine system (IUS) in Finland between April 1990 and December 1993, whose doctors had returned a form at the time of insertion. A total of 17914 replies (75\% response rate) were analysed. The IUS had been removed prematurely from 5175 women. The continuation rates at $1,2,3,4$ and 5 years were $93 \%, 87 \%, 81 \%, 75 \%$ and $65 \%$, respectively. The symptoms most strongly associated with premature removal were excessive bleeding and spotting, and infections and pain. The risk of premature removal was markedly lower in those who had occasional or total absence of menstruation. The authors conclude that the continuation rate of the IUS compares favourably with other longacting contraceptive systems.

****Michael L Cox, FRCOG, MFFP Consultant Obstetrician and Gynaecologist (Retd), Yew Tree Lodge, Main Street, Higham-on-the-Hill, Nuneaton CU13 6AJ 